\title{
Characteristics of tools used in the friction drilling method
}

\author{
Kacper SZWAŁEK, Krzysztof NADOLNY
}

DOI: $10.30464 /$ jmee.2018.2.2.109

Cite this article as:

Szwałek K., Nadolny K. Characteristics of tools used in the friction drilling method. Journal of Mechanical and Energy Engineering, Vol. 2(42), No. 2, 2018, pp. 109-114.

VOLUME 2(42) | No. 2 | JUNE 2018

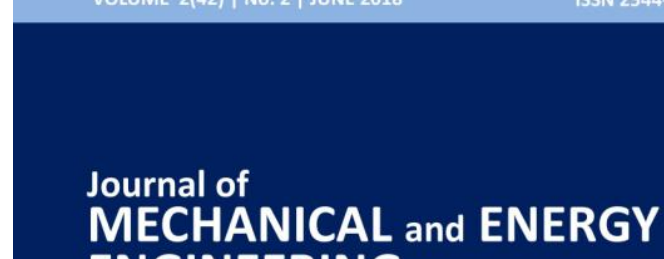
ENGINEERING

Editor-in-Chief

Waldemar Kuczyński

Editors

Krzysztof Rokosz | Krzysztof Nadolny
Journal of Mechanical and Energy Engineering

Website: jmee.tu.koszalin.pl

ISSN (Print): 2544-0780

ISSN (Online): 2544-1671

Volume: 2(42)

Number: 2

Year: 2018

Pages: 109-114

\section{Article Info:}

Received 16 March 2018

Accepted 30 April 2018

\section{Open Access}

This article is distributed under the terms of the Creative Commons Attribution 4.0 (CC BY 4.0) International License (http://creativecommons.org/licenses/by/4.0/), which permits unrestricted use, distribution, and reproduction in any medium, provided you give appropriate credit to the original author(s) and the source, provide a link to the Creative Commons license, and indicate if changes were made. 


\title{
CHARACTERISTICS OF TOOLS USED IN THE FRICTION DRILLING METHOD
}

\author{
Kacper SZWAŁEK ${ }^{1 *}$, Krzysztof NADOLNY ${ }^{2}$ \\ ${ }^{1 *}$ Faculty of Mechanical Engineering, Department of Production Engineering, Koszalin University \\ of Technology, Raclawicka 15-17, 75-620, Koszalin, Poland, e-mail: kacper0191 @ interia.pl \\ ${ }^{2}$ Faculty of Mechanical Engineering, Department of Production Engineering, Koszalin University \\ of Technology, Poland
}

(Received 16 March 2018, Accepted 30 April 2018)

\begin{abstract}
Friction drilling as a non-chip drilling method requires a special formed tool. This tool can be combined with conventional drilling machines as well as milling machines, also CNC ones. The choice depends only on the factors related to production volumes. Tool must have high durability properties to reach proper efficiency level. This means the number of boreholes that can be formed while maintaining the shape and structure of the surface within the dimensions tolerances limits. High temperature in the process also causes high durability properties. These article presents a review of possible solutions on tools mounting devices and tools functionality used in friction drilling process.
\end{abstract}

Keywords: friction drilling, Thermdrill, thin-walled materials, tool durability

\section{INTRODUCTION}

Friction drilling (also known as thermal drilling) is an innovative, non-chip method of drilling. The friction mentioned in the name is the result of contact between the conical rotating tool and the surface of the workpiece. This process has been developed to enable threads to be made in thin-walled materials (plate sheets or profiles) which allow a tight connection without the use of additional connecting elements, such as nitrile threads. The main purpose of friction drilling is to obtain a sleeve with a thickness of three to four times that of the base material [1]. Friction drilling begins when the rotating tool comes into contact with the material (Fig. 1). Under the influence of rotation and feed force, friction is generated which increases the temperature of the material, which can reach up to $750^{\circ} \mathrm{C}$ during the process [2]. The temperature shall increase until the material becomes plastic. The opening is then pressed under the feed force. A tool with a conical geometry gradually expands the hole diameter and lengthens the moulded sleeve. The flow is formed at the end of the process. The shape and size depend on the type and geometry of the tool used, as well as the feed force set.

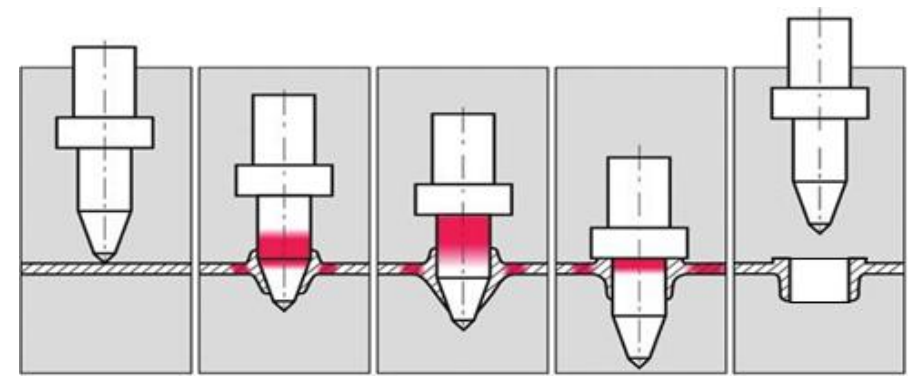

Fig. 1. Scheme of during the friction drilling process [3] 
The friction drilling method does not require any more costs connected with a special machine and equipment purchase. Such a process can be carried out in single cycles on bench drill and conventional machines (Fig. 2), also in automated cycle guaranteed high recurrence using $\mathrm{CNC}$ machines. Tools manufacturers terms only minimal requirements for machines to avail full of tools possibilities.

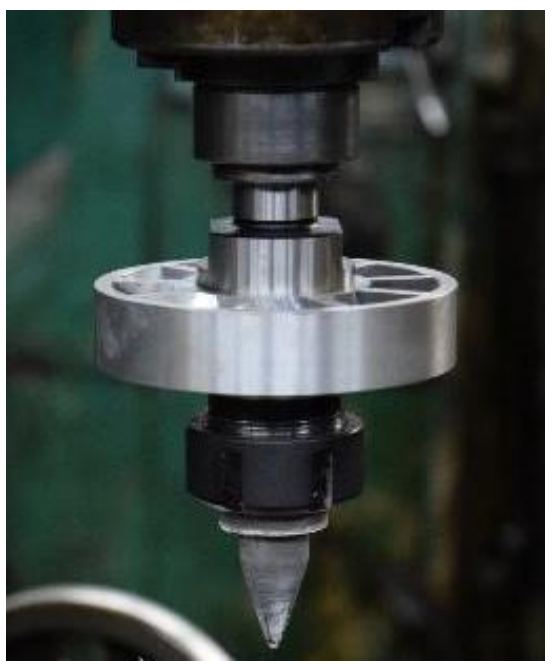

Fig. 2. Friction drilling set mounted on light milling machine AVIA FNC-25 [2]

The main application of the frictional drilling method is threaded joints in thin-walled materials. From this point of view, making holes using the frictional drilling method has features that put this process above the conventional drilling process. Friction drilling is a cheaper and faster process than traditional methods of making holes. This is due to the shorter time of the hole and its subsequent threading of bore. The threaded bore with this method requires only two operations. In the first one, a hole is formed in one passage, while the second one is threaded. In order to achieve a similar effect with traditional methods, the threaded element must be additionally fixed and immobilized. The most frequently used are threaded rivets or special weld nuts, the purchase of which increases the cost of making a single hole. Such a connection does not guarantee either tightness or high strength parameters compared to the thread made in a full material [3]. The differences between the additional threaded elements used and the thread in the full material are shown in Figure 3.

Friction drilling outside the main application has several advantages which are not directly related to the main application of this method, but are worth noting due to their usefulness. One of the factors that reduces costs and time needed to shape a bore is the fact that no coolant is used. This has a significant impact on the environment and operator comfort (no oil vapours). In addition to this, it is possible to use a lubricant mist or special paste, as there is no need for time consuming cleaning of the treated workpiece with chips and remnants of liquids. The high degree of cleanliness of the friction drilling method allows this method to be used for making holes in structures intended for medical or food contact applications.

\section{TOOL HOLDER}

Tolling necessary to friction drilling process realization is a special tool holder with a cooling disc (Fig. 4).

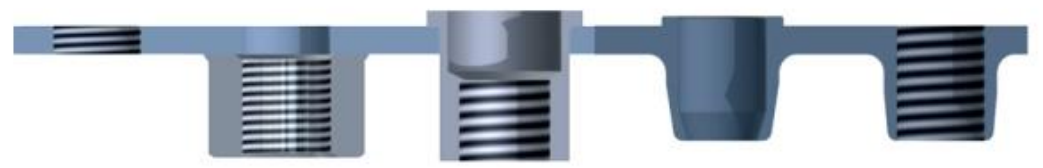

Fig. 3. Differences in threaded connections in thin-walled materials (from left): thread in material; nut welded; nitonated nut; thermally formed hole; thread in moulded material [4]

a)

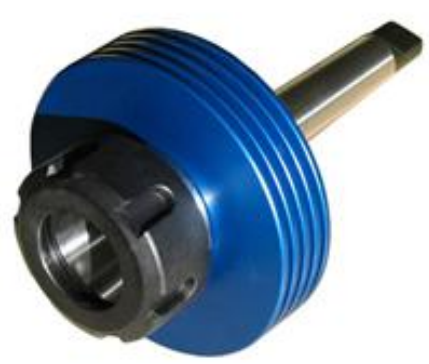

b)

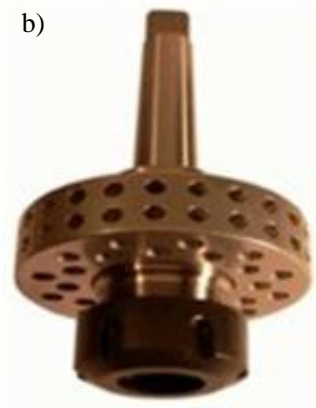

c)

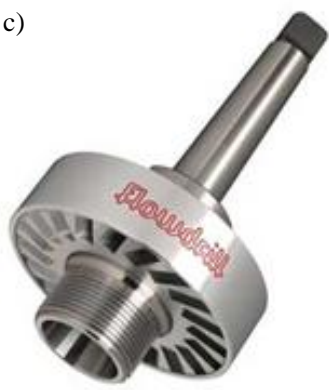

Fig. 4. Example solutions used in cooling discs: a) corrugated cylindrical wall by Macosta; b) disc with bored surface by Parksons; c) turbine construction by Flowdrill $[5,6,7]$ 
During rotational movement, the disc accounts for air movement extortion to up from tooling place. Not using this part causes the tool to degrade faster and decrease quantity of possible to manufacture bores in a time unit. The cause of this state is substantial limitation of heat reception possibilities from tooling material. Moreover, lack of the cooling disc causes a negative influence to the final quality of bores throughout an increase of the heat transfer zone. Increased tooling temperature to phase changes level in tolling material is possible, too. Tool manufacturers use different construction solutions to solve air movement problem, but they work similarly. Despite construction differences, a large majority of manufacturers to mount tools in the holder use the Morse cone. The use of the Morse cone makes the tool clamping system compatible with nearly all types of machine tools [2].

\section{DRILLS}

A main executive element for a friction drilling process is drill. Also named thermdrill or thermoforming drill. This tool has a characteristic conical shape (Fig. 5). Coated carbide with noble elements is the main material used to manufacture thermdrills [8].

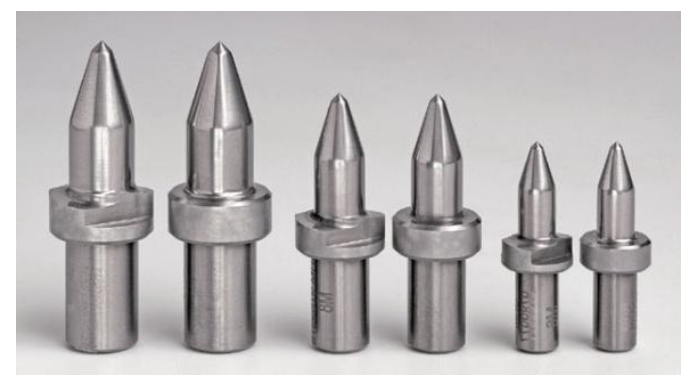

Fig. 5. An exemplary series of friction drilling drills [5]

As friction drilling is usually a pre tapping operation, tool manufacturers do not use tool diameters for making their products. In most cases, the size of the drill bit is determined by determining the thread size to be used in the following order.

Parts of drill shown in Figures 6a-6d have a direct influence to forming bushing and outflow. The part shown in Figure 6e is a gripping part. Drilling begins when the top of the drill has contact with tolling material. Different value $\alpha$ and $\beta$ angle are connected with the change of the peripheral speed to reduce friction force after tooling material puncture and not implement thermal changes into tooling material while forming. View in Figure $6 \mathrm{~d}$ described by dimension $d$ makes a final diameter of drilled bore. Guide a square plane across to rotate axle, it is easy to see a full cylindrical shape and some flat surfaces. It is unique for this type of toll and minimize a adhesion forces. It is necessary to reduce chemical contents changes of drilled bore surface.

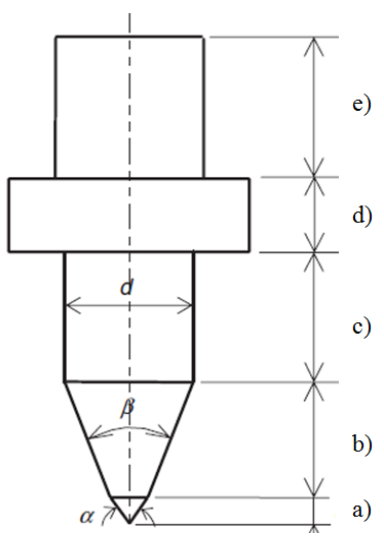

Fig. 6. Structure of thermoforming drill: a) central part; b) conical part; c) cylindrical part; d) bushing forming part; e) gripping part [8]

Usually drills are manufactured in two groups and two kinds (Fig. 7). The first group includes tools formed a unique outflow on the material surface (Fig. $7 b)$. Drills equipped with an acute edge in forming part making a second group (Fig. 7a). This edge evens the surface to level of tooling material around formed bore (Fig. 8). The choice between these groups depends on the future usage of bored hole. Both kinds of drills are manufactured in long and short versions. The long version is used to drill metal sheets. Short versions are dedicated to usage in metal shapes $[5,6$, 7].

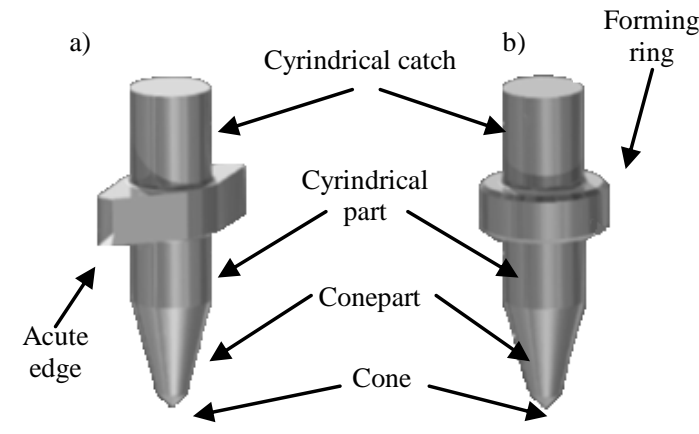

Fig. 7. Kinds of the friction drills: a) with cutter blade; b) formed bushing on a machined material surface[4]

a)

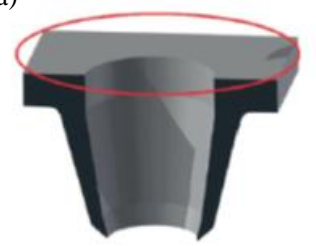

b)

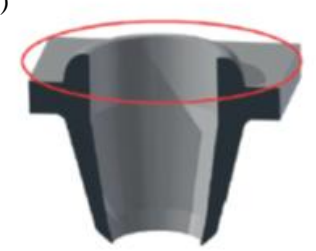

Fig. 8. Possible to reach kinds of bores: a) with flat surface; b) with formed bushing [4] 


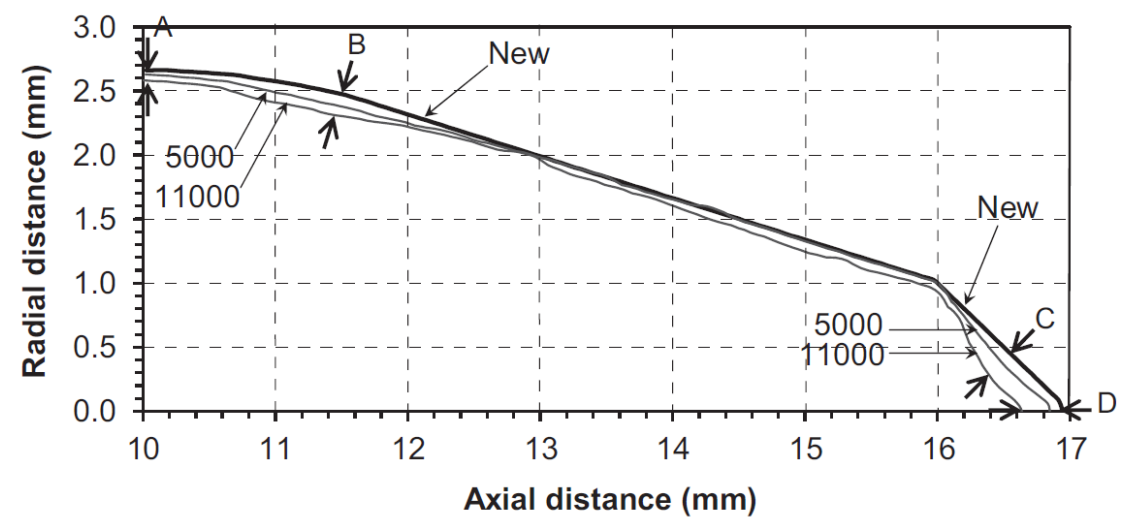

Fig. 9. Diagram of the geometric parameter change according to increasing quantity manufactured holes [8]

\section{TOOL DURABILITY}

The drill is a very durable tool. Right usage with manufacturer care included in the user manual makes it possible to drill thousands of openings. The results of research published in 2006 at the University of Michigan shows a possibility to reach 11,000 drilled bores with one tool (Fig. 9) [8]. Drill lost of the geometrical parameters is relatively marginal. So many drilled bores is an unreachable quantity for multi-cutter head manufactured bores by defect methods. The largest change of drill dimensions occurred in the central part because in this place friction is started and on this part the adhesion forces have the biggest influence. A sharply ended cone after so great an amount of manufactured bores is a significant factor, too. So high level of drill durability is also interesting because this is most temperature exposed element. After use a change of dimension is visible in area B (Fig. 9). In this zone formed bushing part moved to part fixing final diameter of the bore. Is possible to see flattening of chart in this zone.

This kind of changes of the drill geometric can be the cause of conical cross section bores. That shape of bores can be problematic for the other usage of bores than threaded holes. In Figure 10, a microscopic view showed the phases of the drill wear according to the numbers of manufactured bores.

In the various stages of tool wear and tear, measured by the number of holes made, there are visible increasing cracks. Their number increases with the number of holes. The cracks are perpendicular to the axis of rotation of the tool. After 11,000 holes have been made, the scratches are focused on the border between cylindrical part and bushing forming part.

Measuring the diameters of particular drill zones is one of the methods of estimating tool wear. However, this means interrupting the process and waiting for the tool and clamping tool to cool down. This results in lost time and increased downtime costs.
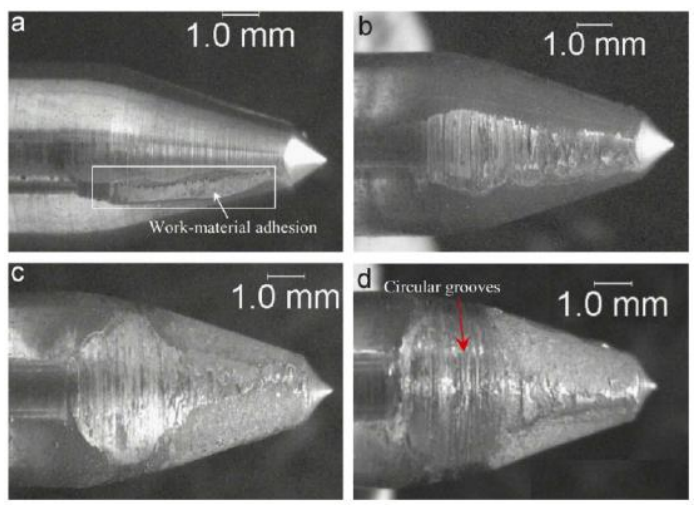

Fig. 10. Level of tool consumption after: a) 2 bores; b) 1000 bores; c) 5,000 bores; d) 11,000 bores [8]

Thermal imaging is an excellent tool for forecasting tool wear. The advantage of this solution is the possibility to record the results on-line. This technology also allows the results to be archived and compared over time. It is also possible to collate the data collected for different tools (different design or material) and to compare them with each other for a specific number of bores they made.

The wear of the tool can be seen in the thermograms by increasing the number of bright spots (Fig. 11 and 12). This is due to the loss of smoothness of the tool as the number of bores increased (Fig. 10). The appearance of lateral scratches reduces the contact area between the tool and the workpiece. In addition, sharp crack edges increase the friction forces in the process. This causes the tool to heat up more intensively on its surface [10]. As we know, overheating of the processing zone is undesirable due to the possibility of structural changes on the surface of the shaped bore. The analysis of recorded thermograms makes it possible to prevent this type of effects, even though the results of tool measurements would still indicate the possibility of its further exploitation. 


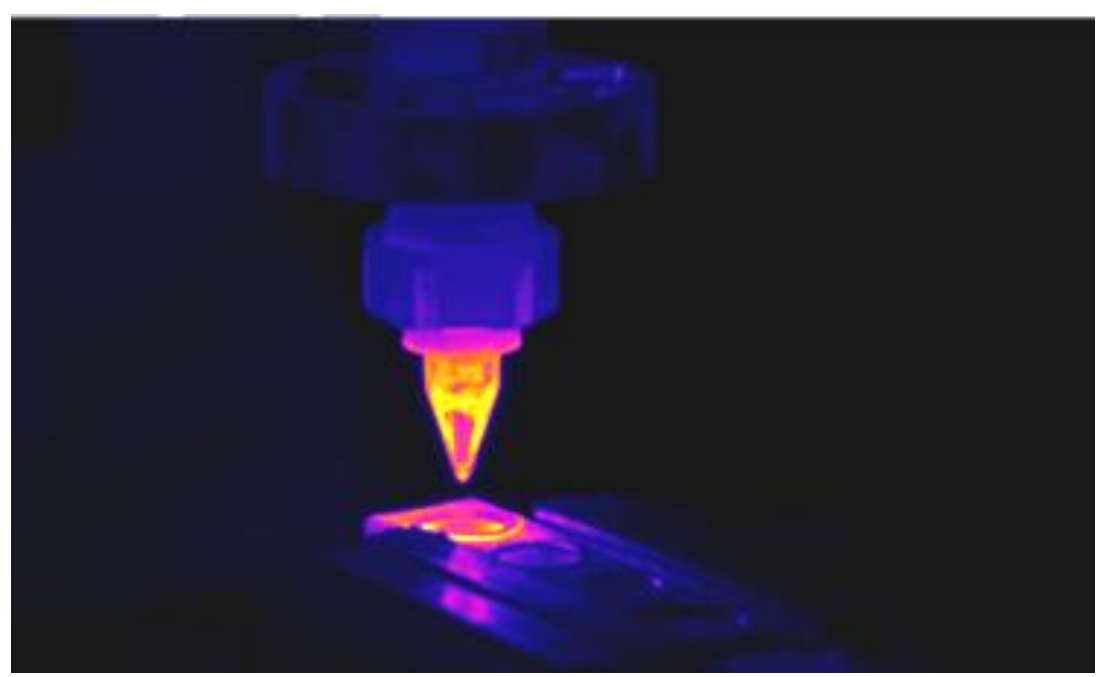

Fig. 11. Example thermal drilling process thermogram - taking after bore shaping [2]

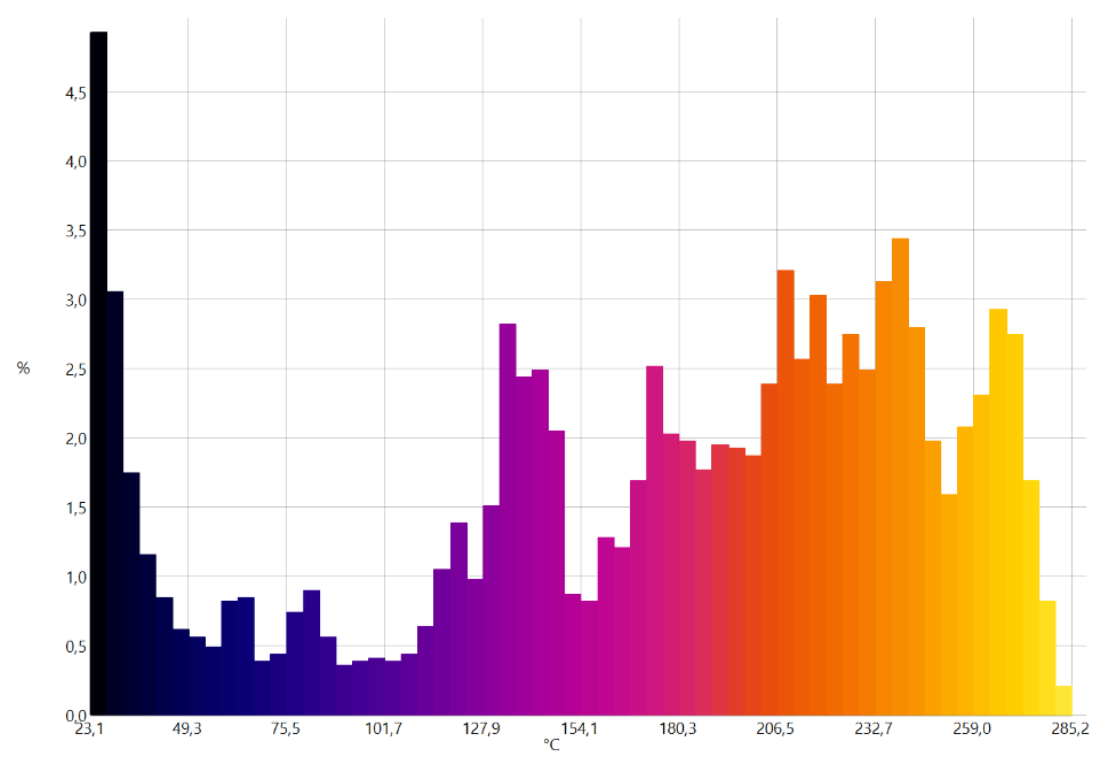

Fig. 12. Example of a histogram drawn up for a tool at the time of exit from the workpiece [2]

An example of a tool that facilitates the analysis of thermograms of the friction drilling process is the temperature distribution histogram for the part of the heat map that is tested. This form of data representation makes it possible to determine the temperature distribution over a given area.

\section{CONCLUSIONS}

The information obtained from literature sources analyzed was useful to form the following conclusions.

1. The friction drilling method can be implemented on conventional machining machines, making it easy to implement.
2. The use of numerically controlled machines makes it possible to achieve high repeatability of the holes made in series and mass production.

3. Despite the different designs, the principle of operation of the cooling discs from different manufacturers is the same.

4. Depending on the future application of the bore, drills are available to make holes with a moulded outflow as well as with a surface aligned to the level of the workpiece material.

5. When making holes in the metal sheets, long drills should be used, which allows a more precise formation of the sleeve. 
6. Bore manufactured on the profiles requires the use of short drills, which prevents the creation of bores on opposite walls of the profiles.

7. Tools used in the friction drilling process obtain high durability allowing for 11000 manufactured bores.

8. Too high a temperature in friction drilling process can be a cause for a structural change of tooling material and fastest wearing of toll.

9. Tolo manufacturers use different solutions for heat repellent from tooling area,

10. With increasing of manufactured bores quantity tool gradually wearing, but characteristic shape of toll remain preserved.

11. Thermal imaging can be carried out on-line and reduces the cost of downtime needed to cool the tool to a safe temperature.

12. The use of thermal imaging cameras in the friction drilling process research allows one to obtain a lot of information about the influence of temperature on the tool wear.

\section{References}

1. Miller S.F., Tao J., Shin J. (2005), Friction drilling of cast metals, International Journal of Machine Tools \& Manufacture, Vol. 46, pp. 1526-1535.

2. Szwałek K., 2017, Experimental studies of thefriction drilling process of stainless steel shapes, Master Thesis, Koszalin University of Technology.

3. EURO-MET Trade Materials

4. STJORSEN Trade Materials

5. Han-Ming C., Shin-Min L., Lieh Dai Y. (2007). Machining Characteristic Study Of Friction Drilling On AISI 304 Stainless Steel. Journal Of Materials Processing Technology, Vol. 207, pp. 180-186.

6. MACOSTA Trade Materials.

7. PARKSONS Trade Materials.

8. FLOWDRILL Trade Materials.

9. Miller S.F., Blau P.J., Shin A.J. (2006). Tool Wear In Friction Drilling, International Journal ofMachine Tools \&Manufacture, Vol. 47, pp. 1636-1645.

10. Krasauskas P., Kilkevičius S., Česnavičius R. Pačenga D. (2014). Experimental analysis and numerical simulation of the stainless AISI 304 steel friction drilling process. Mechanika, Vol. 20, No. 6, pp. 590-595.

\section{Biographical notes}

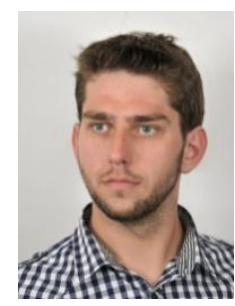

Kacper Szwalek is a Ph.D. student in Department of Production Engineering of Faculty of Mechanical Engineering in Koszalin University of Technology. His first title received in 2015 in the field of Management and Production Engineering. Engineer's thesis discussed about improving of production process of heating device. Nearly two years later he received title Master of Science in Mechanics and Machine Design. Master thesis handled with research about stainless steel friction drilling process. Mainly issue of this studies was identify the relationship between feed rate, rotational speed and shape parameters as well as geometrical structure of the surface. Results of this thesis gave a begin of his Ph.D. studies in Koszalin. He pursues the job of mechanical designer in vacuum technique plant in Koszalin. He design machine parts and components for vacuum food packaging machines, pumps and prepare some other projects for special customers requests.

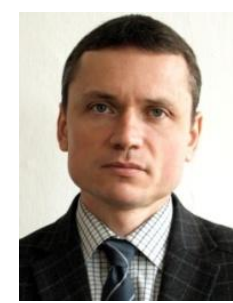

Krzysztof Nadolny received his M.Sc. degree in Mechanics and Machine Design and next Ph.D (with honors) as well as D.Sc. degree in Machinery Construction and Operation from Koszalin University of Technology, in 2001, 2006 and 2013, respectively. Since 2006 he has been a researcher in the Department of Production Engineering at the Koszalin University of Technology, where currently he works as an associated professor and head of research-didactic team for production planning and control. His scientific interests focus on problems concerning machining processes and tools, efficiency, monitoring and diagnostics of machining processes as well as tribology. He has participated in 2 international and 3 national research projects, presenting results of his work at 10 international and 21 national conferences, published more than 200 scientific papers in international and national journals, book chapters, as well as conference proceedings. He is also the author of 4 monographs and 9 national patents. 